\title{
Restauración: entre la técnica y la ciencia. Breve reflexión
}

\author{
Diego Iván Quintero Balbás | El Colegio de Michoacán (México)
}

URL de la contribución <www.iaph.es/revistaph/index.php/revistaph/article/view/3539>

En los últimos años dentro de la restauración se ha comenzado el debate sobre su actuar y las reflexiones en torno a su propia definición, la formación de sus profesionales y su carácter científico. Como resultado, se ha producido un conjunto de trabajos teóricos que en mayor o menor medida han impactado en las formas de intervenir. Las condiciones de los diferentes contextos han permitido que el desarrollo de las ideas teóricas de la restauración tomen características propias.

Llama la atención que en la propuesta del presente debate se mencione al restaurador como un personal técnico -lo cual es común en muchos contextos; por ejemplo, en México, dentro del Instituto Nacional de Antropología e Historia (INAH) los restauradores forman parte del sindicato de técnicos- sobre todo porque en los últimos años se ha luchado por el reconocimiento de la restauración como una disciplina, con un claro fundamento científico. La cual no se basa únicamente en una actividad técnica, sino que requiere de una reflexión teórica para cada uno de los casos en los que se intervienen, sobre sus características, las implicaciones de la intervención y la ganancia de conocimiento que se produce a partir de la intervención.

En México, los debates teóricos han buscado redefinir lo básico de la restauración, desde la revisión crítica de las ideas brandianas, realizada por Rebeca Alcántara (ALCÁNTARA HEWITT, 2000), y las reflexiones sobre el objeto de estudio de la disciplina, de Mauricio Jiménez (JIMÉNEZ RAMÍREZ, 2004) y Mirta Insaurralde (INSAURRALDE CABALLERO, 2008).

Estas reflexiones han dado mayor visibilidad a la crisis teórica en la que, al parecer, se encuentra la disciplina, al menos desde el contexto mexicano, en el que los conceptos de la obra de arte como objeto de estudio de la restauración no se ajustan a la realidad del patrimonio que se aborda.
El carácter científico de las intervenciones y el trabajo bajo un esquema interdisciplinar han tomado mayor importancia como un legitimador científico, sin una real aplicación y sin una reflexión clara sobre los alcances y necesidades para llevar a cabo tales empresas. La sobreutilización de técnicas analíticas, sin preguntas de investigación claras y sin un conocimiento de sus alcances, ha hecho que se tome a la ciencia como un factor que permite justificar la acción del conservador dentro del medio académico. A pesar de esto queda claro, como lo ha hecho notar Alejandro Meza Orozco (MEZA OROZCO, 2014), que la restauración requiere de forma casi obligatoria un trabajo realmente interdisciplinar.

Desafortunadamente, en la práctica esta forma de trabajo no se lleva a cabo en su totalidad. Las razones que muchos de los restauradores mexicanos han dado se refieren a la falta de tiempo, por los cortos plazos establecidos por las instituciones, y a los recursos económicos. Estas constituyen más un pretexto que una realidad, ya que si en la planeación del proyecto se incluyen todos los tiempo y presupuestos necesarios para el análisis de laboratorio, la búsqueda histórica, antropológica, etc., como un paso previo para la elaboración del diagnóstico, quizás la realidad sería diferente. Lo que se hace imperante es la necesidad de un cambio en los paradigmas conceptuales, los cuales guíen las intervenciones y que permitan establecer metodologías más apropiadas para la intervención de los objetos.

A pesar de esto, y aun contando con instituciones encargadas de la protección del patrimonio cultural, nos enfrentamos a intervenciones inadecuadas que han dañado gravemente una gran cantidad de objetos. Queda claro que parte del problema es una falta de conocimiento -al menos en el contexto mexicano y quizás en toda Latinoamérica- de la existencia de una disciplina encargada de la conservación del patrimonio por parte de la sociedad en general. 


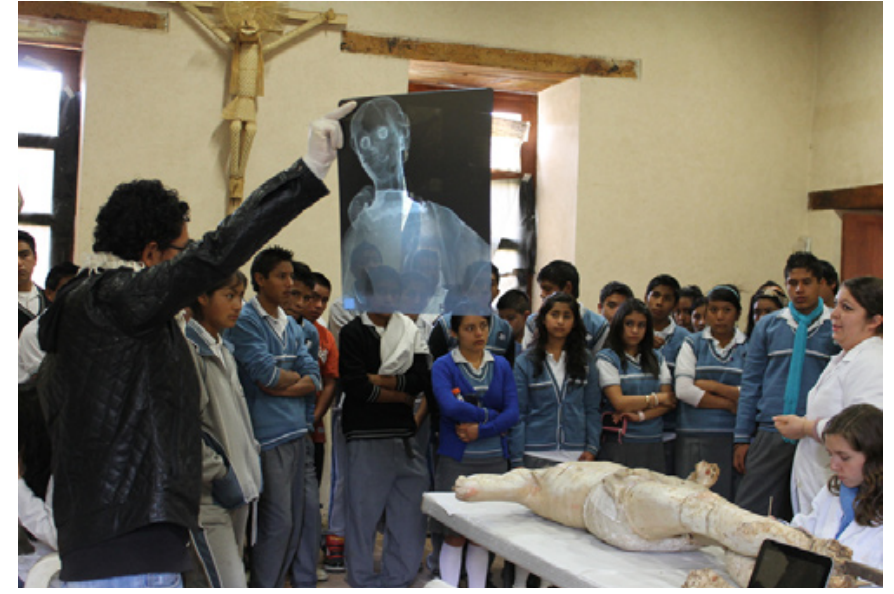

Visita de escolares al taller provisional de conservación en el exconvento franciscano de Tzintzuntzan, Michoacán | foto LADiPA-COLMICH

Esto se refleja en la "intervención" realizadas por personas que no cuentan con la formación necesaria.

Ante esta situación, parece que es necesario un planteamiento teórico que no sólo regule la forma de actuación sino que realmente reflexiones sobre la disciplina. Esta reflexión debe alcanzar el campo de la formación profesional. Afortunadamente en México la oferta educativa a nivel superior en el área de la restauración ha ido en aumento y se ha comenzado a luchar por alejar la visión técnica de la disciplina, reafirmando que se trata de una actividad que produce conocimiento, el cual también es relevante para otras disciplinas como la historia y la historia del arte, sin ser una mera herramienta.

Así pues, consideramos que en la actualidad es necesario que los especialistas sean más conscientes de las implicaciones conceptuales de las intervenciones; de las necesidades de mirar dentro de la misma disciplina y continuar con la reflexión con respecto a sus fundamentos. También es importante continuar con la publicación de los resultados, legitimando a la disciplina como productora de conocimiento y no sólo como una herramienta para otras disciplinas, tratando de alejarse de la visión meramente técnica de la actividad.
El trabajo bajo un esquema interdisciplinario es de suma importancia, no sólo como una muletilla legitimadora de la intervención, sino como una real aplicación metodológica en la que se complementan los saberes de distintas áreas de conocimiento dentro de un diálogo entre pares, y no con un servilismo hacia otras áreas de conocimiento. Si bien es cierto que existe una parte del trabajo principalmente técnica, ésta debe estar respaldada por una diagnosis bien establecida en un conocimiento integral y reflexión real de las condiciones del objeto.

Así solo resta continuar con el debate teórico con el objetivo de definir con mayor claridad la teoría de la disciplina y ver reflejadas dichas ideas en la manera de actuar, no como un modelo normativo sino como una real reflexión conceptual de los problemas que se abordan.

\section{BIBLIOGRAFÍA}

- ALCÁNTARA HEWITT, R. (2000) Un análisis crítico de la Teoría de la restauración de Cesare Brandi. México: Instituto Nacional de Antropología e Historia, 2000. 148 p.

- INSAURRALDE CABALleRO, M. A. (2008) De la obra de arte al patrimonio cultural. Consideraciones para la conceptualización del objeto de restauración. Tesis de licenciatura. México: Escuela de Conservación y Restauración de Occidente, 2008. 190 p.

- JIMÉNEZ RAMíREZ, M. B. (2004) El objeto de la Restauración. Fundamentos teóricos de una práctica. Tesis de licenciatura. México: Escuela Nacional de Conservación, Restauración y Museografía, 2004. 120 p.

- MEzA ORozco, O. A. (2014) Historia del arte $y$ Restauración. Un análisis de la interdisciplina para el estudio de la pintura de caballete novohispana. Tesis de licenciatura. México: Escuela de Conservación y Restauración de Occidente, 2014. 233 p. 